\title{
TITLE: PLASMA GLUCOSE LEVEL IN TRAUMA PATIENTS BASED ON LOCATION
}

AUTHORS: Mitra Jabalameli MD, Khosrou Naghibi MD

AFFILIATION: Department of Anesthesiology and Intensive care, Alzahra General Hospital, Sofe Boulevard, Isfahan, Ira

INTRODUCTION: The metabolic responses to trauma and surgery have been well described.There is increasing data that hyperglycemia correlates with worse outcome in criti-cally ill patients. The purpose of this study is to analyse the relatoinship of plasma glucose $(\mathrm{G})$ on admision with types of trauma, GCS and Trauma Score(TS) in trauma patients.

METHODS: We studied 270 patients admitted to the trauma centre. Plasma G,GCS,TS,types of trauma were checked on admision in all patients.In cases with plasma G (BS1)greater than $140 \mathrm{mg} / \mathrm{dl}$, next 24 hours plasma G (BS2) was checked.

RESULTS: The incidence of trauma types and their mean BS1 include: head and neck $(45 \%, B S 1=238 \pm 104 \mathrm{mg} / \mathrm{dl})$, abdominal and chest $(7.4 \%$, BS1 $=200 \pm 89 \mathrm{mg} / \mathrm{dl})$, pelvic $(2 \%, \mathrm{BS} 1=152 \pm 10 \mathrm{mg} / \mathrm{dl})$, extremities $(16.1 \%, \mathrm{BS} 1=140 \pm 12 \mathrm{mg} / \mathrm{dl})$, multiple trauma(28\%,BS1=193 $\pm 82 \mathrm{mg} / \mathrm{dl})$.Mean plasma $\mathrm{G}$ in patients with $\mathrm{TS}=13-16, \mathrm{TS}=8$ 12 and $\mathrm{TS}<8$ was130.74, 273.78, $340 \mathrm{mg} / \mathrm{dl}$ respectively.

DISCUSSION: The findings suggest that in the emergency stage of trauma hyperglyc emia occurs in all types of trauma. Also plasma G increased with TS and degree of injury as reflected in GCS $(\mathrm{P}<0.05)$.

\section{REFERENCES:}

1) J Trauma . 35:271

2) Am J surg.163:283

3) Crit care clin .17:107 